\title{
Awareness of Medical Students at Al-Imam University of the Medical Uses and Benefits of Honey
}

\author{
Talal T. Abo Al-Jadayel ${ }^{1}$, Abdulrahman Abo Salamah ${ }^{2}$, Salman SafaHagi ${ }^{3}$, Mohamed aqeel Al-Ghamdi ${ }^{4}$, \\ Yousef Mahmoud Alyamany ${ }^{5}$, Abdulhakim Ali Alkhodair ${ }^{6}$, Anas M. Alhasoun ${ }^{7}$, Abdullah S. Aloraini ${ }^{8}$, \\ Hamzza S. Ghazal ${ }^{9}$
}

1, 2, 3, 4, 7, 8, 9 Intern, College of Medicine / Al-Imam Mohammed IBN Saud, Riyadh- Saudi Arabia

${ }^{5,6}$ College of Medicine/ King Abdulaziz Medical City and Hospitals, Riyadh- Saudi Arabia

\begin{abstract}
Aim: To assess the knowledge of Al-Imam Mohamed Ibn Saud University, collage of medicine undergraduate students about complementary and prophet medicine in general. And the uses of honey in different medical specialty. Identifying weak areas since the complementary medicine is a block of 5 weeks length is added to the student's curriculum. To improve final outcome of the block. Prove that honey affect different aspect of health positively. Methodology: We conducted a cross sectional study were a total of 100 questioner where distributed over 100 undergraduatestudents. The undergraduate studentswere selected randomly (systemic random sampling) based on the attendance sheet of the first, second and third year in medical college in the first semester of 2013. We decided to take thirty percent of each year randomly. Repeated students were excluded from the sample and replaced by other student same method of choosing the other proved students. Result: Data were collected by a questioner filed by 100 undergraduate student from first, second and third year in collage of medicine at Al-Imam Mohammed Ibn Saud University. Collected data were analyzed later. The undergraduate students were subdivided based on their grade point average. 3-3.5/5 (10\%), 3.5-4/5 (50\%), 4-4.5/5 (25\%) and >4.5/5 (15\%). We found the 55\% of the approved sample have good background about the honey usage and the benefits in different medical aspect. 40\% of those who know honey benefits and medically uses use honey daily. The rest of the populations were ranging from one time per week to one time per month. Conclusion: honey has proved that if affect the health in different aspects and have proved that it can be used as an immune system builder, wound and burns healing, gastric disorders, sore throat, dental care, anti-cancer agent and weight loss diets. Since the study was done in Al-Imam Mohammed Ibn Saud University, collage of medicine. We found that more than 50 percent of the students have a fair knowledge about medical uses and benefits of honey, the higher the GPA the higher the knowledge. Also from our view as undergraduate student we see that we can improve the complementary medicine block outcome by converting most of the lecture given by doctors to seminars conducted by students to maximize the overall benefit. Conduct a problem base learning sections so the student have more chances to increase their knowledge while they are searching and reading for facts on a given subject.
\end{abstract}

Keywords: Honey, Complementary, Medicine, Student.

\section{Introduction}

Thousands of years ago, honey was used by humans. Cave painting was found in Spain from 7000 years bc was the earliest records for beekeeping. A temple near Cairo, Egypt showed evidences that ancient Egyptians used honey as sweeteners for their kings. Greek viewed honey not only as important food but also as medications $(1,2,3)$.

We conducted a research on a small group of undergraduate students at Al-Imam Mohammed Ibn Saud University, collage of medicine to look for the facts and evidence based knowledge about honey benefits and their medical uses in different health aspects. Later we decided to know how popular these information about honey benefits is over undergraduate students at Al-Imam Mohammed Ibn Saud University, collage of medicine.

We found that honey can be used as immune system booster, anti-bacterial, wound healing, sore-throat and cough, and as an anti-cancer (1.2.3).

A study was done in 2016 by Farbes. Ta. onchildren who need a PD(peritonealdialysis) where they will need an exit wound on their abdominal wall for a long period of time.
The International guidelines for PD recommends that the application of mupiracin on the exit wound of PD. So what he did is presenting 8 pediatric patients with poor exit wound condition, persistent infection and he applied honey over the wound exit. Whit time he noticed that the use of honey was producing a remarkable improvement on the exit site. As he says, at the meantime Medihoney is the first line prophylactic exit-site ointment in PD exit site at their institution (4).

Mucositis, is inflammation and ulcers formation following chemotherapy in children. Makes us as doctors working hard to find solutions to prevent it. That what Kobya B. did when he conducted an experimental study about prevention of Mucositis by using honey after chemotherapy. He found that the regular oral care with honey in children's un dergoing chemotherapy for hematological cancers prevents mucositis and also accelerate the recovery(6).

One of the latest studies proving the honey as an antibacterial against MRSA is a study published in May, 2016 by Medeiros. He took 24 rats and divided them into four 4 groups each have six rats. The 1 st group was had no infected wound and treated with normal saline only, the 2nd group not infected wound and treated with honey only, 3rd group 


\section{International Journal of Science and Research (IJSR) \\ ISSN (Online): 2319-7064}

Index Copernicus Value (2015): 78.96 | Impact Factor (2015): 6.391

had infected wound and treated with NS(normal saline) and 4th group had infected wound and treated with honey. Observing them for seven days, on the seventh day he took tissue biopsy which revealed high TNF, IL-6 and IL-1 in the 4th group. He concluded that honey have enhanced cytokine expression and had positive influence on the wound healing (5).

Manuka honey powder was examined on infected wound showed anti-microbial effect not against MRSA only but also against S.pyogenes $(5,8,9)$.

Evidence's of the role of honey in wound healing were too much to cover in this research. One of them is the study done back in Jan, 2016 by Dart C. he was investigating the effectiveness of using Manuka honey in treating contaminated wounds. He found that the used honey decreased wound inflammation, increase angiogenesis and fibrosis / collagen organization. Indeed, treating with Manuka honey gel resulted in more organized granulation tissue bed early in wound repair which may contribute to enhancing healing of the wound (7).

It is also proved that Manuka honey enhances fibroblasts and therefore improve wound healing (7).

Benefits for respiratory tracks and system were also approved. $\mathrm{MH}$ (Manuka honey) was tested on patients complaining of chronic rhino-sinusitis prior to surgery and it did show a significant improvement and good outcomes (11).

In another study, they compared honey syrup and carbocysteine cough syrup. It was showed that both syrup were tolerated in children's over two years. The honey syrup was associated with more rapid and greater improvement in all clinical symptoms measured, beginning from the first night of the therapy. Nocturnal and day-time symptoms of cough were improved (12).

A published study was on pumped since April, 2015 about efficacy of the se of GH (gelas honey) in people with positive Ras/ERK pathways (a well-known to play a major role in colon cancer). Tahir T. and his colleagues examined the GH on colon cancer cells and they conclude that it may be an effective chemo-preventive and therapeutic strategy for inducing death to colon cancer cells $(13,14)$.

Another research done by a researcher called Hakim T. also supports what Tahir did conclude in his research but he found that $\mathrm{GH}$ enhances anti-cancer effect of 5-FU (5flurouracill) against colorectal cancers $(13,14)$.

\section{Method}

In this study we used a conducted cross-sectional study. The study was done at the college of medicine in Al-Imam Mohamed Ibn Saud University, which was found in 1953 and now is considered one of the largest universities in Riyadh the capital city in Saudi Arabia the university is organized into many different colleges teaching different sciences like Islamic Sciences, engineering, language, and medicine. . The study included the undergraduate students who are in the first, second, and third years of medical school from the male section of the college only because, by the time the study was conducted, the female section of the college of medicine was not found yet. Thirty percent of the students of each year were selected randomly using a systemic random sampling based on their attendance sheet in the first semester of 2013. Repeated students were excluded from the sample and replaced by other students by the same method of choosing the other proved students. A total of 100 questionnaires, which included demographics and specific questions that aim to assess the knowledge of Al-Imam Mohamed Ibn Saud University college of medicine undergraduate students about the complementary and prophet medicine in general. And the uses of honey in different medical specialty, were distributed to 100 undergraduate students, who met the inclusion criteria mentioned above, in this study. The data, that was collected in this study, was analyzed appropriately using frequencies in percentages.

\section{Results}

By collecting 100 questionnaires, which have been distributed to students from the 1st, 2nd, and 3rd, year, who are studying at Al-Imam University, we have formed our database.

The Questionnaire included questions that concerned honey usage in daily diet, medical uses of honey, general knowledge about honey, and a question regarding the GPA of the student for us to correlate the answers of the previously mentioned questions with the relative performance indicator- which is the GPA- of the student's academic pursuit.

The GPA of the students were as following:

$50 \%$ of the students had a GPA of 3.5-4

$25 \%$ had a GPA ranging between 4.0-4.5

$15 \%$ of the students had a GPA that was above 4.5

$10 \%$ had GPA's falling between 3.0-3.5

The majority were average students of GPA's that do not Exceed 4.0 out of 5 .

We found that students with $>4.5$ GPA (15\%) have consistently answered most of the general knowledge questions correctly than students with lesser GPA's. This correlates their academic performance with both the studied curriculum and their knowledge base concerning complementary medicine, as well as basic medical knowledge used in common practice to a lesser degree.

\begin{tabular}{|c|c|c|c|c|c|}
\hline $\begin{array}{c}\text { GPA } \\
\text { out of 5 }\end{array}$ & $\begin{array}{c}\text { Correctly } \\
\text { answered } \\
\text { 1st } \\
\text { question }\end{array}$ & $\begin{array}{c}\text { Correctly } \\
\text { answered } \\
\text { 2nd } \\
\text { question }\end{array}$ & $\begin{array}{c}\text { Correctly } \\
\text { answered } \\
\text { 3rd } \\
\text { question }\end{array}$ & $\begin{array}{c}\text { Correctly } \\
\text { answered } \\
\text { 4th } \\
\text { question }\end{array}$ & $\begin{array}{c}\text { Correctly } \\
\text { answered } \\
\text { 5th } \\
\text { question }\end{array}$ \\
\hline $3.0-3.5$ & $43 \%$ & $50 \%$ & $56 \%$ & $40 \%$ & $20 \%$ \\
\hline $3.5-4.0$ & $55 \%$ & $65 \%$ & $50 \%$ & $60 \%$ & $18 \%$ \\
\hline $4.0-4.5$ & $68 \%$ & $73 \%$ & $79 \%$ & $85 \%$ & $39 \%$ \\
\hline$>4.5$ & $82 \%$ & $90 \%$ & $88 \%$ & $91 \%$ & $70 \%$ \\
\hline
\end{tabular}

(Figure 1)

\section{Volume 6 Issue 1, January 2017




\section{International Journal of Science and Research (IJSR) \\ ISSN (Online): 2319-7064 \\ Index Copernicus Value (2015): 78.96 | Impact Factor (2015): 6.391}

- Figure 1 represents the percentage of students who answered each of the general knowledge questions correctly, grouped by their GPA. The questions numbered are the following by respective order:

- 1-Does honey help building up the immune system?

- 2-Can honey be used as antibacterial and antiinflammatory?

- 3-Is honey used for wound healing?

- 4-Is honey good for relieving a sore throat?

- 5-Is honey safe for ingestion by infants?

From all the students, 30\% were 1 st year student, $46 \%$ were 2nd year students, and 24\% 3rd years students. Making our study more focused on younger students in order to analyze how early on do they usually acquire this kind of information.

Of all the students who participated in the questionnaire, the majority reported that they use honey frequently, and the lesser minority reported that they do not use honey, or rarely do.

$78 \%$ use honey.

$22 \%$ don't use honey or rarely do.

Students who reported using honey on a daily or near daily basis were $20(20 \%)$. Of the students who used honey on a daily or near daily basis, $8(40 \%)$ of them were using it because they had an idea about honey being a healthy nutrient, whether it was from parental advice, religious, cultural, or completely scientific reasons.

The questionnaire included a question regarding the reason of honey use by the student if they frequently use it.

$75(75 \%)$ said because it is a healthy nutrient

$20(20 \%)$ Did not specify, by saying they liked it

$5(5 \%)$ reported that the reason they used it most likely would be because of its taste.

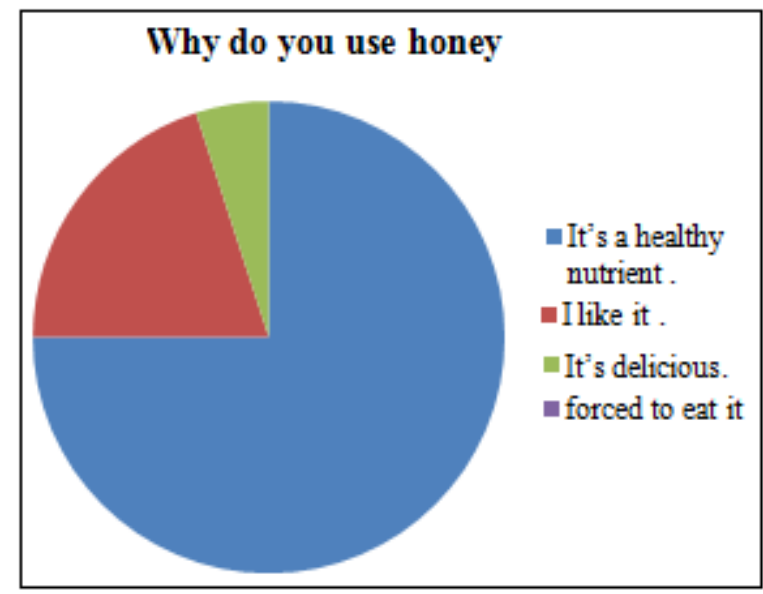

(Figure 2)

Frequency of usage ranged from daily use, to less than once per month

\section{$25 \%$ of them use it at least once or twice a week.}

And $15 \%$ of them use it at least once every two weeks.

$40 \%$ use the honey at least once a month.

$20 \%$ do not use the honey at all.

Adding to a total of approximately $80 \%$ of students reporting honey use at least once a month. The questions that we have asked pertaining to general knowledge about honey were the following:

Does honey help building up the immune system?

The correct answer is yes, according to the articles we have reviewed.

Students who answered correctly amounted to 60 students $(60 \%)$

With $40(40 \%)$ answering incorrectly

Can honey be used as antibacterial and anti-inflammatory?

The correct answer was yes, based on the reviewed and discussed literature.

$65(65 \%)$ of them answered (yes)

$20(20 \%)$ answered (I don't know)

$15(15 \%)$ answered (No)

Is honey used for wound healing?

The correct answer is yes based on the literature we have reviewed proving that honey has a role in the wound healing process.

$60(60 \%)$ answered (yes)

$30(30 \%)$ answered (I don't know)

$10(10 \%)$ answered (no)

Is honey good for relieving a sore throat? :

The correct answer is yes based on our literature review.

$70(70 \%)$ answered (yes) correctly

$15(15 \%)$ said (No)

15 (15\%) (I don't know).

Is honey safe for ingestion by infants?

As it is known and proven by several studies, honey should not be given to infants due to it containing Clostridium Botulinum bacteria, which is able to survive on, and resist honey's antimicrobial mechanisms. Due to the child's lack of complete intestinal maturity, including the normal flora, an infant would have a very good chance of colonization and infection by $\mathrm{C}$. Botulinum causing a type of flaccid paralysis.

So, the correct answer in this case would be no.

$30 \%$ answered (Yes)

$40 \%$ answered (No),

$30 \%$ answered (I don't know). 
International Journal of Science and Research (IJSR)

ISSN (Online): 2319-7064

Index Copernicus Value (2015): 78.96 | Impact Factor (2015): 6.391

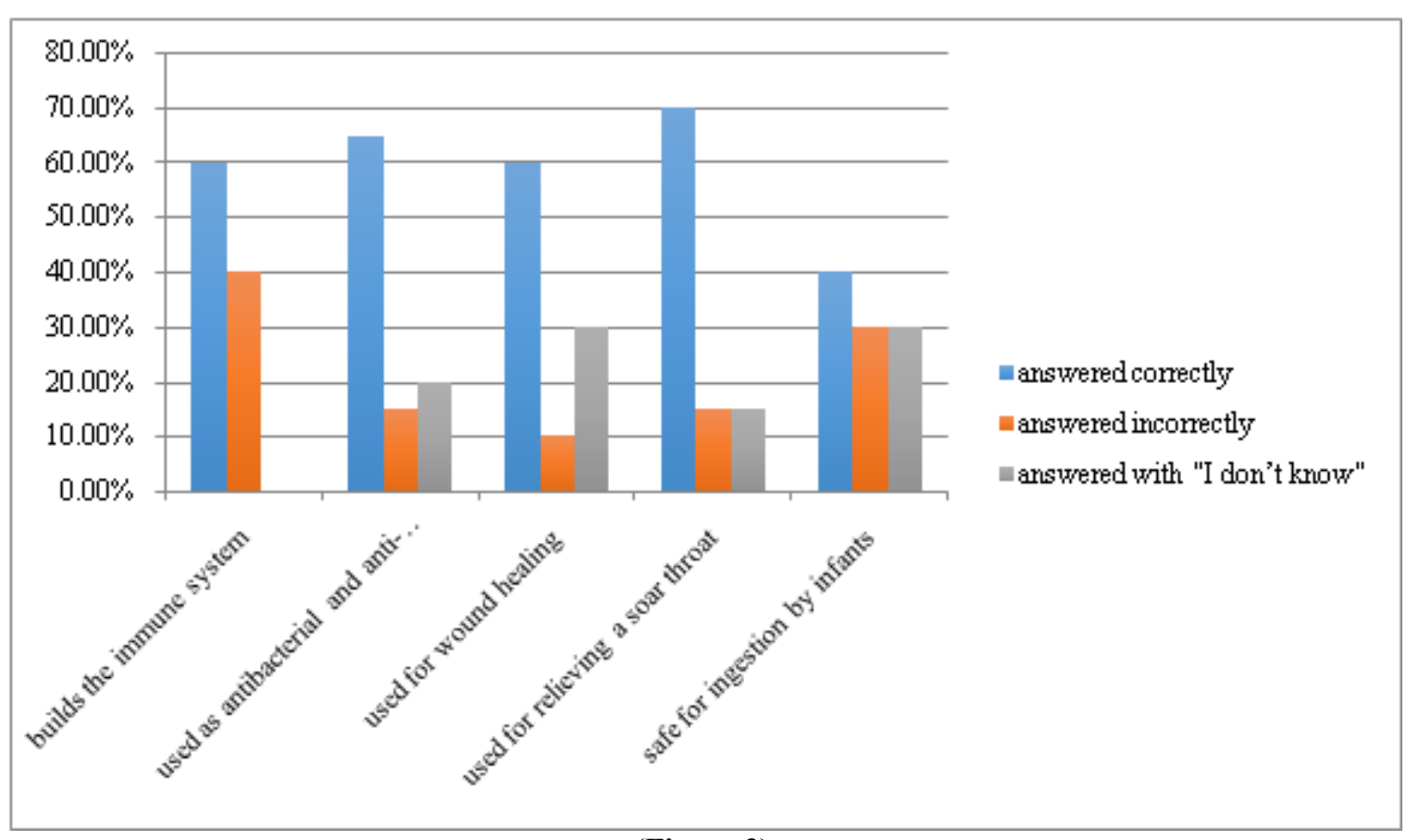

(Figure 3)

This graph represents the questions that were asked on the horizontal axis, and the performance of the students in answering these questions correctly on the vertical axis.

Overall, we could say that $55 \%$ of the population has a background about the uses of honey as a medical treatment.

\section{Discussion:}

We have begun by distributing and collecting 100 questionnaires to and from Al-Imam University in Riyadh city, Kingdom of Saudi Arabia, which contain questions that pertain to general knowledge about honey, medical facts concerning honey, along with questions regarding daily use of honey, and dietary facts.

The answers of the students were correlated with both their GPA and their then current year in Medical school. Our study was more focused on younger students in order to analyze how early on do they usually acquire this kind of information, with the exceeding majority of students filling the questionnaire being $1^{\text {st }}$ and $2^{\text {nd }}$ year students $(76 \%)$, along with average students with the majority of all students having GPA's that do not exceed 4.0 out of $5(60 \%)$.

Students with higher GPA's consistently answered correctly compared to the students with lower GPA's, this reflects upon a curriculum and grading system that truly represent both the general and academic performance of the students, with the majority of right answers coming from the group with GPA's higher than 4.5 our of 5 .

When we asked about honey usage, a small minority reported consistent near-daily consumption (20\%) and of them a small minority claimed that the main reason for this was because of their knowledge of it being a healthy nutrient $(40 \%)$.
This shows that the general knowledge acquired regarding honey, whether from academic, cultural, religious, or scientific, can be positively informative in that it leads to acting upon this information by the regular consumption of honey by the minority mentioned regardless of how small the group is in contrast.

However, when we asked all the students, regardless of whether they consume honey on a near-daily basis or not, about the main reason for using honey if they did, and the answer that was reported the most was because it was a healthy nutrient $(75 \%)$, this reflects the true impact of the aforementioned influences on our application of acquired knowledge in daily life activities such as honey consumption, but in contrast to the previously discussed percentage pertaining to regular users of honey, it does not show us the percentage that consistently applies this knowledge in their daily diet which add up to only $(8 \%)$ of the whole sample.

When we reviewed the answers for the questions regarding General knowledge of honey, in all questions the majority of students answered correctly when compared to the students who answered incorrectly, but that excludes the students who answered with "I don't know". When we take all students' answers in perspective we find that when comparing the correct answers with the sum of both the incorrect and the neutral - answered as "I don't know" - the exceeding majority answered correctly except for the last question ( $5^{\text {th }}$ question) which was " is honey safe for ingestion by infants, with these percentages comparing correct to incorrect or neutral answers.

$1^{\text {st }}$ question: $60 \%$ correct, $40 \%$ incorrect or neutral $2^{\text {nd }}$ question: $65 \%$ correct, $35 \%$ incorrect or neutral $3^{\text {rd }}$ question: $60 \%$ correct, $40 \%$ incorrect or neutral $4^{\text {th }}$ question: $70 \%$ correct, $30 \%$ incorrect or neutral $5^{\text {th }}$ question: $40 \%$ correct, $60 \%$ incorrect or neutral (see Figure 3) 


\section{International Journal of Science and Research (IJSR) \\ ISSN (Online): 2319-7064}

Index Copernicus Value (2015): 78.96 | Impact Factor (2015): 6.391

To summarize we could say that by viewing these results it is safe to assume that around $55 \%$ of the sample representing the population has some medical background regarding the use of honey as a treatment method. We can also conclude that there is evidence of measurable benefit from both the medical curriculum and the complementary medicine block in utilizing the knowledge acquired via these methods in real application in life.

\section{Conclusion}

When we started this research we thought that the majority of the students would not have much information about treating with honey and the benefits of it. But after we review the answers of the questioner we used and the survey, we found that more than fifty percent of the undergraduate students have a fair background. The higher the GPA the higher the knowledge. Since Al-Imam Mohammed Ibn Saud University, collage of medicine provide a mandatory complementary medicine block of five week long and a high percentage of undergraduate student have a below expectation knowledge about honey benefits we suggested some points from our view as undergraduate students such converting most of the lectures given by doctors to seminars given by students with supervision of qualified and expert doctors, conduct problem base learning sections to which will provide more knowledge to the students while they are reading and searching for facts, encourage the student to look for evidence based facts.

In our trip of completing this research looking for proved benefits of honey. We found so much researches that prove that honey have the ability to affect health in different aspects positively. We found researches that prove the honey as an immune system builder, wound healing, gastric disorders, sore-throat, dental care, anti-cancers and weight loss diets. After we have all that evidences we would love to increase the awareness of the society about honey benefits as a natural product.

\section{References}

[1] "The taxonomy of recent and fossil honey bees (Hymenoptera: Apidae: Apis)". Journal of Hymenoptera Research. 8: 165-196.

[2] Charles W. Whitfield, Susanta K. Behura , Stewart H. Berlocher, Andrew G. Clark, J. Spencer Johnston, Walter S. Sheppard, Deborah R. Smith, Andrew V. Suarez, Daniel Weaver \& Neil D. Tsutsui (2006). "Thrice out of Africa: ancient and recent expansions of the honey bee, Apismellifera".

[3] Han, Fan; Wallberg, Andreas; Webster, Matthew T (2012). "From where did the Western honeybee (Apismellifera) originate?". Ecology and Evolution. 2 (8): 1949-1957. Retrieved 14 December 2016.

[4] Forbes, T., Shaw, L. and Quinlan, C. (2016). Topical Honey in the Management of Pediatric Peritoneal Dialysis Exit Sites. Peritoneal Dialysis International, 36(6), pp.684-687.

[5] Medeiros, V., Azevedo, Í.,Rêgo, A., Egito, E., AraújoFilho, I. and Medeiros, A. (2016). Antibacterial properties and healing effects of Meliponascutellaris honey in MRSA-infected wounds rats. ActaCirurgicaBrasileira, 31(5), pp.327-332.

[6] Kobya Bulut, H. and GüdücüTüfekci, F. (2016). Honey prevents oral mocositis in children undergoing chemotherapy: A quasi-experimental study with a control group. Complementary Therapies in Medicine, 29, pp.132-140.

[7] Bischofberger, A., Dart, C., Horadagoda, N., Perkins, N., Jeffcott, L., Little, C. and Dart, A. (2016). Effect of Manuka honey gel on the transforming growth factor $\beta 1$ and $\beta 3$ concentrations, bacterial counts and histomorphology of contaminated full-thickness skin wounds in equine distal limbs. Australian Veterinary Journal, 94(1-2), pp.27-34.

[8] Tenci, M., Rossi, S., Bonferoni, M., Sandri, G., Mentori, I., Boselli, C., Cornaglia, A., Daglia, M., Marchese, A., Caramella, C. and Ferrari, F. (2016). Application of DoE approach in the development of mini-capsules, based on biopolymers and manuka honey polar fraction, as powder formulation for the treatment of skin ulcers. International Journal of Pharmaceutics, 516(1-2), pp.266-277.

[9] Tenci, M., Rossi, S., Bonferoni, M., Sandri, G., Boselli, C., Di Lorenzo, A., Daglia, M., IcaroCornaglia, A., Gioglio, L., Perotti, C., Caramella, C. and Ferrari, F. (2016). Particulate systems based on pectin/chitosan association for the delivery of manuka honey components and platelet lysate in chronic skin ulcers. International Journal of Pharmaceutics, 509(12), pp.59-70.

[10] Cooper, R. (2016). Honey for wound care in the $21 \mathrm{st}$ century. Journal of Wound Care, 25(9), pp.544-552.

[11]Lee, V., Humphreys, I., Purcell, P. and Davis, G. (2016). Manuka honey sinus irrigation for the treatment of chronic rhinosinusitis: a randomized controlled trial. International Forum of Allergy \& Rhinology.

[12] Cohen, H., Hoshen, M., Gur, S., Bahir, A., Laks, Y. and Blau, H. (2016). Efficacy and tolerability of a polysaccharide-resin-honey based cough syrup as compared to carbocysteine syrup for children with colds: a randomized, single-blinded, multicenter study. World Journal of Pediatrics.

[13] Tahir, A., Sani, N., Murad, N., Makpol, S., Ngah, W. and Yusof, Y. (2015). Combined ginger extract \&Gelam honey modulate Ras/ERK and PI3K/AKT pathway genes in colon cancer HT29 cells. Nutrition Journal, 14(1).

[14] Hakim, L., Alias, E., Makpol, S., Ngah, W., Morad, N. and Yusof, Y. (2014). Gelam Honey and Ginger Potentiate the Anti Cancer Effect of 5-FU against HCT 116 Colorectal Cancer Cells. Asian Pacific Journal of Cancer Prevention, 15(11), pp.4651-4657. 